\title{
Improving Global TBI Tracking and Prevention: An Environmental Science Approach
}

\author{
Mara Chen ${ }^{1}$, Karl Maier ${ }^{2}$, Donna Ritenour ${ }^{3} \&$ Christina Sun $^{4}$ \\ ${ }^{1}$ Henson School of Science \& Technology, Salisbury University, Maryland, USA \\ ${ }^{2}$ Fulton School of Liberal Arts, Salisbury University, Maryland, USA \\ ${ }^{3}$ College of Health and Human Services, Salisbury University, Maryland, USA \\ ${ }^{4}$ College of Computer, Mathematical, and Natural Sciences, University of Maryland, Maryland, USA \\ Correspondence: Mara Chen, Henson School of Science \& Technology, Salisbury University, Salisbury, MD \\ 21801, USA. E-mail: mxchen@salisbury.edu
}

Received: July 24, 2021 Accepted: January 13, 2022 Online Published: January 27, 2022

doi:10.5539/gjhs.v14n3p20 URL: https://doi.org/10.5539/gjhs.v14n3p20

\begin{abstract}
Traumatic brain injury (TBI) has grown to pandemic proportions, placing a significant burden on global public health, socio-economic condition, and human capital resources. This paper examines the global spatial distribution of TBI using currently available data from research studies to advance a comprehensive review of TBI that integrates geospatial and environmental perspectives. It reveals significant geographic differences and socioeconomic gaps in global TBI incidence tracking, prevalence, and mortality rates. It proposes an environmental science approach to improving public awareness, tracking and prevention of TBI through the integration of environmental data using GIS. The use of GIS for accurate location-based mapping and integrated analysis of environmental data subsequently helps reveal risk factors for targeted research, education outreach, and more effective public health policy and preventative measures.
\end{abstract}

Keywords: TBI, TBI Tracking and Prevention, Global Health, Health and Environmental Pespective

\section{Introduction}

As we face the acute crisis of COVID-19, another global public health pandemic has silently emerged in recent years - traumatic brain injury (TBI). In the U.S., TBI has often been considered a silent epidemic due to its many subtle effects and the general lack of public awareness. Yet, TBI has become a critical public health problem and a significant socio-economic burden throughout the world: It is prevalent in both low- and high-income countries and affects people of all ages and a leading killer of children in the developed and developing world (Peeters et al., 2015; Bell et al., 2017). A comprehensive geospatial approach is needed to better address TBI - a problem that is perhaps best understood by the very nature of our relationships with the environment throughout human history.

Traumatic brain injuries directly affect our critical executive organ, our human intelligence hub. The injuries sustained from head trauma stem from our inability to prevent or adequately adapt in real time to abrupt environmental changes encountered in daily living, which may be naturally occurring or human-induced (Chen et al., 2020). In a parallel progression, human ecological habitats have evolved from natural caves to nomadic shelters, tribes, cities, and metropolises, to emerging intelligent cities with digital grids beyond physical infrastructure and traditional spatial boundaries. Deep geological history has shown a vital story of major and minor adaptations of organisms to environmental challenges. In our short human history, we have also experienced and adapted to tremendous environmental challenges, either naturally occurring and/or human induced, such as the Ice Age, great floods, volcanic eruptions, dust storms, and infectious diseases. Many societal advancements are largely propelled by the evolution of human intelligence and ingenuity along with our adaptations to environment, such as agriculture cultivation, industrialization, automotive transportation, distant wireless communication, computing, and artificial intelligence (AI). The TBI problem highlights the vital importance of human-environment interactions and calls for better intelligent design of safer environments, and the maximization of resources for TBI awareness and prevention.

Toward this, we take a broader view of the global TBI problem to promote improvements in TBI tracking and prevention. The biopsychosocial concept continues to evolve toward a more ecological understanding of health, such that biological, psychological, and social factors interact at many levels of analysis (Maier \& al'Absi, 2017). 
The physical and social environmental dimensions that can be uniquely integrated by geospatial analysis are essential to more fully understanding and preventing TBI. We analyzed available data in these areas to support our call for environment-based research and education measures on TBI awareness and prevention.

\section{Current Challenges of Global TBIs}

Traumatic brain injury is reported as a leading killer of children in both the developed and developing world (Bell et al., 2017), and the leading cause of global death and disability, more than any other traumatic insult (Dewan et al., 2018). According to the U.S. Centers for Disease Control and Prevention (CDC), TBI in the U.S. affects the young and old the most. From 1990 to 2016, the TBI age-standardized prevalence has increased by 8.4\% (GBD 2016 Traumatic Brain Injury and Spinal Cord Injury Collaborators, 2019). Globally, it is currently estimated that 69 million people sustain a TBI each year, a leading cause of worldwide death and disability; however, TBI incidence and distribution across regions and socioeconomic divides remain unknown (Dewan et al., 2018). Another study indicates that approximately half of the population will likely have one or more TBIs over their lifetime (Maas et al., 2017).

It is estimated that over 50 million adults in the US have experienced a disability, and TBI is one of the leading causes of disability (Courtney-Long et al., 2013). Research in 16 European countries indicates that TBI causes a substantial burden to victims, their families, and society (Majdan et al., 2017). Moderate and severe TBI cause major neural impairments and deficits in mental function. Most patients of moderate TBI regain consciousness, but the long-term cognitive and functional deficit is largely unknown (Vitaz et al., 2003). Previous research shows that survivors of moderate to severe TBI have approximately a $25-35 \%$ reduction in maximal aerobic capacity 6-18 months post-injury (Washnik et al., 2019). TBI causes systemic health problems, often affecting multisensory functions such as vision, hearing, skin sensitivity, overall physical balance, and mobility, in addition to the cognitive and emotional problems from direct brain impact. Long-term prognosis of severe TBI and recurrent TBIs remains less than optimistic. Brain tissue loss from moderate to severe TBI is estimated on the order of $5 \%$ per year; atrophy-induced deformations may trigger a negative feedback loop, causing further deformation (Harris et al., 2019).

The long-lasting impact on the quality of life of patients, their families, and broader socio-economic burdens are simply beyond calculation. The life quality of TBI victims can be severely disturbed or truncated by associated morbidity and mortality. Recent studies estimate that people with short-term mild to severe TBI experience health losses of $11.0 \%$ and $21.4 \%$, respectively, compared with a person in full health, measured by years of life lived with disability (GBD 2016 Traumatic Brain Injury and Spinal Cord Injury Collaborators, 2019). It is estimated that TBI has contributed, on average, $41 \%$ (44\% in males and 34\% in females) to overall injury years of life lost (YLLs), meaning that about 1.3 million YLLs were attributable to TBI in the EU-28 in 2013 (Majdan et al., 2017). In addition, an array of psychiatric disorders, including depression, anxiety, and substance abuse are prevalent after TBI, more so with moderate to severe cases (Juengst et al., 2017). Mental illness after surviving TBI compounds public health problems.

The global economic burden of road injuries alone in the 166 countries included in a study is projected to increase to $\$ 1.8$ trillion (2010 US\$) from 2015 to 2030 (Chen et al., 2019). TBI incidences will likely continue to increase due to factors of growing population density, aging, increased use of motor vehicles, motorcycles, and bicycles (GBD 2016 Traumatic Brain Injury and Spinal Cord Injury Collaborators, 2019). The proportion of TBIs from road traffic injuries are highest in Africa and SE Asia (Dewan et al., 2018). Research suggests a multidisciplinary approach may likewise be optimal for treatment and rehabilitation (Katarzyna et al., 2019). Therefore, it is pertinent to highlight the importance of research efforts on geospatial, physical, and social environmental factors for better TBI prevention.

\section{Spatial Differentiations in Global TBIs}

Given the increased global economic burden of TBI, it is equally important to highlight the spatial differentiations of the distribution of the economic burden and the capacity to deal with it. There are wide differentiations in the cause, prevalence, and mortality rate of TBI among regions and nations. First, the leading cause varies. According to the CDC, falling is the leading cause of TBI in the United States, while road injury remains dominant cause of TBI in the developing countries. TBI results mainly from road accidents in the most populous and rapid developing countries, such as China and India (Maas et al., 2017; Maas, 2017). The dynamics between people and their environment varies greatly from place to place. Major environmental factors include population density, socio-economic conditions, education, employment, transportation infrastructure, road condition, social order and human interactions, population stratification and aging, access to drugs and weapons, and mental health issues. Low- and middle-income countries (LMICs) experience nearly three times more cases of TBI proportionally than high income countries (HICs), even though total TBI incidence is highest in North America (Dewan et al., 2018). 
Based on data from the GBD 2016 Traumatic Brain Injury and Spinal Cord Injury Collaborators, different spatial patterns emerge. Table 1 shows several spatial and social patterns: 1). The top five countries with the highest TBI incidence are India, China, Russia, Brazil, and Pakistan. India, China, and Brazil are of high population density and experiences rapid economic transformation during the study period. 2). Syria has both the highest age-standardized rate (ASR) and the highest percentage increase of ASR (PCASR) in TBI, and the constant civil conflicts might have been an important factor. Several other nations in the same category also experienced political changes and social instability, such as Yemen, Iraq, Afghanistan. 3). The five countries of low ASR and decreased percentage change of ASR or negative PASR (from 1990 to 2016) are nations of higher social stability, such as UK and Japan. This data only shows the patterns of highest TBI incidences and changing rates during the study period from 1990 to 2016. There is a real need for more social science research efforts on the reasons and factors behind the changes within each country.

This study carried out a comparative analysis of TBI mortality rate between 16 European countries and the U.S. TBI data for the year 2013, based on the data availability. The 2013 European TBI data came from the research of cross-sectional analysis of 16 European countries (Washnik et al., 2019) and the 2013 U.S. TBI data was extracted from the Centers for Disease Control and Prevention. Overall, the senior population had the highest TBI mortality rate.

Various chi-squared analyses were carried out, such as among different age groups, among the 16 different European nations, and between the 16 composite European nations (total numbers) and the U.S. total TBI cases. All $p$ values are close to 0 , which indicate that the spatial and age-group variations are all statistically significant. The chi-squared analysis of three European countries with the highest TBI death counts is shown in Table 2, and the chi-squared analysis of the 16 European nations and the US TBI mortality data is shown in Table 3 . Based on the results, it is reasonable to project that the differences between developed countries and developing countries are also significant, if data were available.

Table 1. Global TBI incidence patterns and trends, 1990-2016

\begin{tabular}{|c|c|c|c|c|c|c|}
\hline \multirow{2}{*}{ Country } & \multirow{2}{*}{$\begin{array}{l}2016 \text { Highest } \\
\text { Incidences }\end{array}$} & \multirow{2}{*}{$\begin{array}{l}2016 \\
\text { ASR }\end{array}$} & \multirow[t]{2}{*}{ Highest } & \multirow{2}{*}{$\begin{array}{l}\text { Highest } \\
\text { PCASR }\end{array}$} & \multicolumn{2}{|c|}{ Low AST with negative PCASR } \\
\hline & & & & & AST & PCASR \\
\hline India & 5641697 & & & & & \\
\hline China & 4339654 & & & & & \\
\hline Russia & 1202502 & & & & & \\
\hline Brazil & 786433 & & & & & \\
\hline Pakistan & 745843 & & & & & \\
\hline Syria & & 1322 & & & & \\
\hline Slovenia & & 1092 & & & & \\
\hline Czech Republic & & 1022 & & & & \\
\hline Poland & & 893 & & & & \\
\hline Slovakia & & 889 & & & & \\
\hline Syria & & & & 424.8 & & \\
\hline Yemen & & & & 99 & & \\
\hline Iraq & & & & 67.2 & & \\
\hline Afghanistan & & & & 63.3 & & \\
\hline North Korea & & & & 56.4 & & \\
\hline Timor-Leste & & & & & 235 & -26.3 \\
\hline UK & & & & & 260 & -5.9 \\
\hline Japan & & & & & 263 & -15.5 \\
\hline Portugal & & & & & 267 & -29.3 \\
\hline Liberia & & & & & 270 & -61.6 \\
\hline
\end{tabular}

Data source: Extracted from the GBD 2016 Traumatic Brain Injury and Spinal Cord Injury Collaborators article (Dewan et al., 2018).

ASR: age-standardized rate per 100,000.

PCASR: percentage change in age-standardized rates, 1990-2016. 
Table 2. Chi-squared analyses of the three European nations, with the highest TBI death counts in 2013

\begin{tabular}{llllll}
\hline Age-group & Italy & United Kingdom & Romania & Total & P Value \\
\hline $0-4$ & 22 & 26 & 31 & 79 & \\
$5-14$ & 29 & 18 & 33 & 80 & \\
$15-34$ & 594 & 361 & 276 & 1231 & $p<0.001$ \\
$35-64$ & 1063 & 881 & 923 & 2867 & \\
$65+$ & 2973 & 2472 & 664 & 6109 & \\
Total & 4681 & 3758 & 1927 & 10366 & \\
\hline
\end{tabular}

Table 3. Chi-squared analyses of the 16 European nations and the U.S. 2013 TBI deaths

\begin{tabular}{lllll}
\hline TBI Age Category & European 16 Nations & U.S.A. & Total & P Value \\
\hline $0-4$ & 119 & 760 & 879 & \\
$5-14$ & 152 & 724 & 876 & \\
$15-34$ & 2079 & 12964 & 15043 & $p<0.001$ \\
$35-64$ & 5436 & 20529 & 25965 & \\
$65+$ & 9263 & 20943 & 30206 & \\
Total & 17049 & 55920 & 72969 & \\
\hline
\end{tabular}

Sources: The U.S. data is from the CDC, and the data of the 16 European nations is adapted from Majdan et al., 2017.

\section{Environmental Variables as an Essential Component of Global TBI Data Infrastructure}

Environmental parameters should be an essential component of any TBI database, in addition to current TBI variables, such as causes, severity, age, and gender. The environmental variables need to include both physical and social parameters. Physical variables might include factors like geo-referenceable location, topography, weather, road condition, and transportation mode. Social variables could cover employment status, urban or rural settings, neighborhood characteristics, and ethnicity.

The spatial variability of TBI across different continents and countries calls for more effective tracking and prevention strategies by taking geospatial and social environmental factors into consideration. Measurement of the burden of TBI in greater geographic and demographic detail is of substantial value (GBD 2016 Traumatic Brain Injury and Spinal Cord Injury Collaborators, 2019). However, complete TBI databases at a national level do not currently exist or some national TBI data are not available for the research community to access. Approximately 10 million of moderate-to-severe TBI annually is estimated in India, yet there remains a major need of data to study TBI (Maas, 2017)

Continuous data tracking of TBI incidences has only been available in the U.S. and certain European countries over the past few decades. TBI data are almost absent in low- and middle-income countries (LMICs) where TBI is likely to occur much more frequently (Maegele, 2019). It is both crucial and feasible for all nations to document and track TBI incidences, with the use of modern technologies and similar digital formats and guidelines.

Lacking complete and compatible data is a major problem in global TBI tracking, and inconsistency in currently available data compounds the problems in studying TBI incidences and mortality. The U.S. and many European countries have decades of TBI data tracking and reporting. However, the TBI data collection and analyses across Europe and the U.S. still have wide variations and discrepancies in the reported incidences and mortality rates (Maegele, 2019; Li et al., 2016; Majdan et al., 2016; Maas et al., 2017).

\section{A GIS Framework of TBI}

Geographic Information System (GIS) is known for its capability in location-based mapping and integrated geospatial analysis. It has been widely used in location-based mapping and geospatial analyses of features and events at different scales and in many disciplines. It has been effectively used in epidemiology and public health for providing sophisticated spatial analysis of disease occurrence, cancer data and other health data, geostatistical data analysis of interconnected health and contributing environmental risk factors (Rytkönen, 2004; Kontopantelis et al., 2015; Davies et al., 2016; Cho et al., 2020). The increasing utilization of GIS has transformed health in 
disease infectious diseases surveillance and tracking, public health management, and citizens data input (Davenhall \& Kinabrew, 2012; Saran et al., 2020). Geographic information system and artificial intelligence (AI) offer immense possibilities for improving community health and healthcare (Shaw \& McGuire, 2017; Kirby et al., 2017; Boulous et al., 2019; Wang, 2020). Geospatial analyses using GIS help address the geographic distribution of a disease and delineate potential patterns and trends of disease incidences (Nayak et al., 2021).

For example, GIS has played a critically important role in mapping and communicating the daily spatial clustering and temporal trend of the ongoing COVIS-19 (Dong et al., 2020; Ahasan \& Hossain, 2021). Geospatial mapping and analysis on diseases occurrences and interrelationships of the diseases and associated environmental factors help us better understand the causes, trends, and underlying risk factors.

In this vein, we need to take on the challenges of the TBI epidemic in the same way that we deal with other public health threats and any other types of environment disasters, through both proactive/anticipatory and reactive approaches using GIS technology. Currently, health care professionals, the research community, and decision-makers have largely focused on TBI treatment and subsequent management. Much progress has been made in TBI treatment and management in developed countries, but such improvement has not been seen significantly in developing nations where the risk factors are among highest. Historically, increased awareness, optimal management and guidelines, and significant technological advancements in current treatment regimens resulted in an overall TBI-related death rate (Harvey \& Close, 2012)

Still, the prevalence of global TBI is increasing. Limited research efforts have focused on anticipatory strategies, i.e., how to better track and prevent TBI in the first place. Leading causes of TBI vary significantly from country to country and across demographical age groups. Falling is the leading cause of TBI for older adults (Nykiforuk \& Flaman, 2021), while TBI due to accidents or sports is a leading cause of death and disability in children and young adults in the United States (U.S. National Institute of Health). Road injury remains dominant cause of TBI in the developing countries, especially TBI following road traffic collision is more common in LMICs (Dewan et al., 2018).

Traumatic brain injuries have become an urgent and important public health issue. Important public health questions need to be addressed: where did TBI occur? How did they happen? Are there any spatial and temporal patterns and trends of TBI? What are possible important risk factors? Geographic Information System can be effectively used to address these questions if TBI incidences are tracked and coded with georeferenced locations. Geographic Information System can create different types of maps by overall TBI incidences, by cause, by time, by severity, by different spatial scales (local, city, regional, national, global), by age group, and so on. Integrated TBI health data and environmental data analysis help reveal risk factors. These maps and analysis results would then become important for public health communication and decision making.

The use of GIS as a geospatial mapping and analysis tool has become particularly effective and timely relevant in tracking and mitigating the COVID-19 global pandemic (Franch-Pardo et al., 2020). In a similar vein, the use of GIS in TBI as a mapping and analytical tool can lead to three major beneficial outcomes: developing a better global TBI data infrastructure (Chen et al., 2020), improving TBI tracking and promoting better public awareness by using accurate and complete geospatial TBI databases, and formulating more effective prevention measures (Figure 1). 


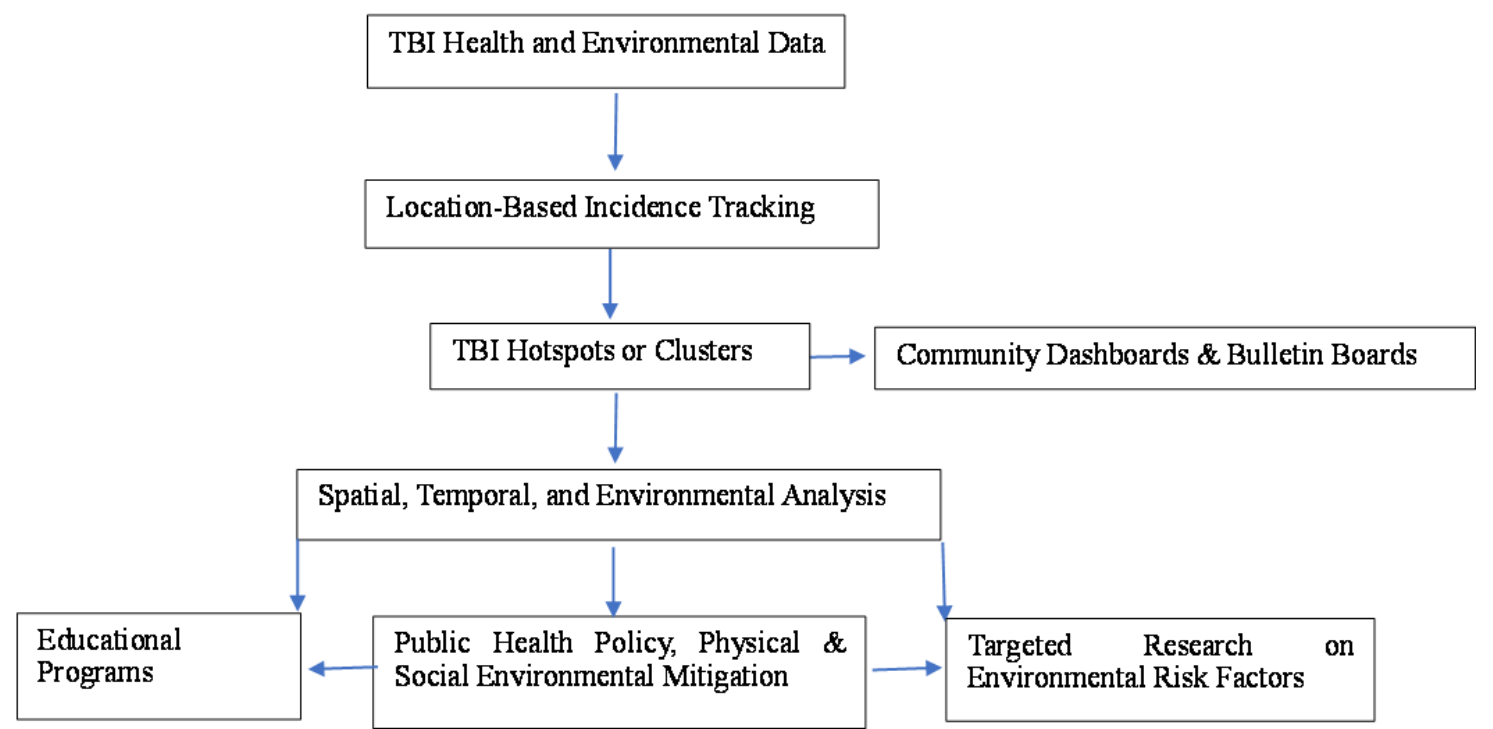

Figure 1. Framework of using GIS in improving TBI tracking and prevention

\section{GIS for Integrated Environmental Analysis and TBI Prevention}

Geographic Information System is not only an effective tool to tracking disease occurrences and create maps for visualization, but is also a robust system to process, analyze, integrate, and model complex incidence data to reveal spatial and temporal patterns, as well as correlations between TBI and different physical and social environmental variables. Integrated environmental analysis can be used for TBI prevention in major aspects: reveal important environment risk factors, promote public awareness and educational measures, and improve better public health policy and effective TBI mitigation strategies.

First, potential environmental risk factors for public health problems can be revealed (Ijumulana et al., 2020; Bhuiyan et al., 2020; Long et al., 2020). As such, there are different causes behind TBI hotspots due to varied environmental factors. If TBI clusters are related to road injuries from vehicle accidents, GIS can be used to analyze TBI occurrences in the context of road condition, topographic slope, weather condition, travel speed, visibility, in addition to a driver's condition and behavior. If TBI clusters in a crime-prone neighborhood, GIS analysis can focus on the potential linkages to social environmental factors, such as unemployment, education, drug use, and violence. For TBI clusters in schools or recreational areas, GIS could be used to identify possible facility and human action and interaction factors behind sports-related injuries. If TBI clusters in elderly people from falls, GIS could be used to analyze the factors related to living environment arrangements, types of activities, time of activities, and health conditions. Using GIS for mapping and environmental analysis can help delineate TBI hotspots and identify possible vulnerable groups and associated risk factors. More personal, clinical, and environmental data are increasingly becoming available for research, and accessible data source for identifying clinical associations and environmental patterns could lead to a better understanding of TBIs (Cobb et al., 2018; Mollayeva et al., 2019). Geospatial and temporal patterns of TBIs may indicate potential correlations with environmental factors and human activities and behaviors.

Second, once TBI incidences and possible environmental risk factors are identified and mapped out, the mapped clusters of concentrated TBI can present geospatial distribution patterns and temporal trends. These maps and information can be put on a community web dashboard and channel into news media, as part of periodic public health announcements to promote public awareness. Environmental analysis using GIS has been used for public health promotion (Nykiforuk \& Flaman, 2021).

In addition to promote public awareness using community dashboard and news media, integrated environmental analysis result can further facilitate targeted research and proactive education programs, based on the identified risk factors. Traumatic brain injury education measures can be an immense catalyst for promoting positive changes. Schools are ideal settings for promoting health, beyond individual behavioral changes, and turning schools into health-promoting settings is a form of sound social investment (Gugglberger, 2021). Traumatic brain injury educational outreach can start anywhere from childhood to adulthood, i.e., from kindergarten through college. Each stage can have a different but somewhat overlapping focus for sustaining improvement on TBI awareness and prevention education. For example, a "Safety ABC", from head to toes, can be designed as a health concept for 
children K-5. For early teens, the focus should be placed more on holistic personal safety (physical, emotional wellbeing, and mental health) and social interaction interpersonal safety (driving, sports, entertainment). In college, education should center around autonomy, body, mind, and environmental ecology management (nutrition, psychological development, social environmental ecology, and public services). All these approaches would promote TBI awareness and prevention among children and youths.

Third, the integrated analysis of both physical and social environmental data would allow decision makers to develop community-oriented public health policy and mitigation strategies. The use of GIS technology provides the most effective for decision-making in a multi-disciplinary context to facilitate sharing of data, knowledge, and expertise (Joyce, 2009). The combined utilization of GIS and remote sensing data has improved knowledge of climatic, environmental, and biodiversity factors, and the research has facilitated decision-making processes for allocating limited resources, mapping risks, and creating early warning systems against vector-borne diseases such as malaria, visceral leishmaniasis, dengue, Rift Valley fever, schistosomiasis, Chagas disease and leptospirosis (Ceccato et al., 2018). The prevalence and varied nature of TBI cases are highly environment dependent, and GIS data integration and analysis would lead to a better decision making and more effective preventative strategies. For example, TBI hotspots are associated with road injuries are prevalent in LMICs (Dewan et al., 2018), decision makers can then better decide if a community needs to set up road warning signs, reconstruct certain segments of road network, install wireless camera monitoring systems, or tighten travel speed limits at certain locations. For TBI hotspots related to social environment instability and complex social dynamic conflicts, it could be more important and effective to provide public health counseling educational seminars, and behavior interventions coupled with more frequent public safety patrol and social outreach programs. For the TBI hotspots of older patients from falling, it would be more effective to alleviate or prevent some falling problems by designing safer living environment and reducing alone activity time.

\section{Discussion and Conclusion}

The rapid economic development and imbalanced dynamic interactions between humans and their changing environment has led to what is essentially a global TBI epidemic. Subsequently, the TBI epidemic has caused major socio-economic interruptions and dysfunctions. It causes not only individual suffering, but also a tremendous global socio-economic burden.

The effectiveness of any preventative health policy depends on appropriate, timely identification and mitigation of major causes and risk factors. The common leading causes of TBI are known, but highly variable both geographically and temporally, within a country and across the globe. Integrated physical and social environment studies using GIS is important and effective in mapping out TBI hotspots and revealing the correlations between TBI incidences and environmental risk factors. The integrated data analysis of TBI and environment risk factors would help promote public health education and formulate better public health policy and specific TBI prevention guidelines to target causes in high incidence areas.

People from the worldwide can greatly benefit from interdisciplinary environmental research beyond medical studies on the TBI causes, treatment and rehabilitation. The effective uses of GIS in COVID-19 and vector-borne diseases surveillance and early warning offer a great promise for its broader applications in TBI research. Geographic information system can delineate TBI spatial distribution hotspots and temporal shifting trends and reveal associated complex environmental variables. Convergent research efforts from medical researchers, environmental scientists, and GIS professionals would provide comprehensive science data and knowledge of TBI causes and contributing environmental risk factors.

Interdisciplinary or transdisciplinary research would help develop better public health policies and more effective TBI prevention strategies on how to create a safer environment, heightened human conscious awareness, and better human and environment dynamics. The preventative measures will lead to safer design and uses of assisted living facilities, athletic gears, as well as road infrastructures and vehicles. Professionals in different science disciplines and health care fields and policymakers can collaborate on specific educational content and mitigation strategies. TBI is one of the most urgent global public health challenges. Integrated environmental science approach will help improve global TBI awareness and prevention.

\section{Competing Interests Statement}

The authors declare that there are no competing or potential conflicts of interest.

\section{References}

Ahasan, R., \& Hossain, M. M. (2021). Leveraging GIS and spatial analysis for informed decision-making in COVID-19 pandemic. Health policy and technology, 10(1), 7-9. https://doi.org/10.1016/j.hlpt.2020.11.009 
Bell, M. J., Adelson, P. D., \& Wisniewski, S. R. (2017). Challenges and opportunities for pediatric severe TBI-review of the evidence and exploring a way forward. Child's nervous system, 33(10), 1663-1667. Epub 2017 Sep 6. PMID: 29149394. https://doi.org/10.1007/s00381-017-3530-y

Bhuiyan, M. A. H., Karmaker, S. C., Bodrud-Doza, M., Rakib, M. A., \& Saha, B. B. (2021). Enrichment, sources and ecological risk mapping of heavy metals in agricultural soils of dhaka district employing SOM, PMF and GIS methods. Chemosphere, 263, 128339. Epub 2020 Sep 15. PMID: 33297265. https://doi.org/10.1016/j.chemosphere.2020.128339

Boulos, M. N. K., Peng, G., \& VoPham, T. (2019). An overview of GeoAI applications in health and healthcare. International Journal of Health Geographics, 18(1), 1-9. https://doi.org/10.1186/s12942-019-0171-2

Ceccato, P., Ramirez, B., Manyangadze, T., Gwakisa, P., \& Thomson, M. C. (2018). Data and tools to integrate climate and environmental information into public health. Infectious diseases of poverty, 7(1), 1-11. PMID: 30541601; PMCID: PMC6292116. https://doi.org/10.1186/s40249-018-0501-9.

Chen, S., Kuhn, M., Prettner, K., \& Bloom, D. E. (2019). The global macroeconomic burden of road injuries: estimates and projections for 166 countries. The Lancet Planetary Health, 3(9), e390-e398. https://doi.org/10.1016/S2542-5196(19)30170-6

Chen, M., Ritenour, D., \& Maier, K. (2020). Enhancing the US TBI data infrastructure: geospatial perspective. Annals of GIS, 26(3), 311-318. https://doi.org/10.1080/19475683.2020.1744724.

Cho, J., You, S. C., Lee, S., Park, D., Park, B., Hripcsak, G., \& Park, R. W. (2020). Application of Epidemiological Geographic Information System: An Open-Source Spatial Analysis Tool Based on the OMOP Common Data Model. International journal of environmental research and public health, 17(21), 7824. https://doi.org/10.3390/ijerph17217824

Cobb, A. N., Benjamin, A. J., Huang, E. S., \& Kuo, P. C. (2018). Big data: More than big data sets. Surgery, 164(4), 640-642. https://doi.org/10.1016/j.surg.2018.06.022

Courtney-Long, E. A., Carroll, D. D., Zhang, Q. C., Stevens, A. C., Griffin-Blake, S., Armour, B. S., \& Campbell, V. A. (2015). Prevalence of disability and disability type among adults-United States, 2013. MMWR. Morbidity and mortality weekly report, 64(29), 777. https://doi.org/10.15585/mmwr.MM6429a2

Davenhall, W. F., \& Kinabrew, C. (2012). GIS in Health and Human Services. Springer Handbook of Geographic Information, 557-578. https://doi.org/10.1007/978-3-540-72680-7_29

Davies, T. M., Jones, K., \& Hazelton, M. L. (2016). Symmetric adaptive smoothing regimens for estimation of the spatial relative risk function. Computational Statistics \& Data Analysis, 101, 12-28.

Dewan, M. C., Rattani, A., Gupta, S., Baticulon, R. E., Hung, Y. C., Punchak, M., ... \& Park, K. B. (2018). Estimating the global incidence of traumatic brain injury. Journal of neurosurgery, 130(4), 1080-1097. https://doi.org/10.3171/2017.10.JNS17352

Dong, E., Du, H., \& Gardner, L. (2020). An interactive web-based dashboard to track COVID-19 in real time. The Lancet infectious diseases, 20(5), 533-534. https://doi.org/10.1016/S1473-3099(20)30120-1_

Franch-Pardo, I., Napoletano, B. M., Rosete-Verges, F., \& Billa, L. (2020). Spatial analysis and GIS in the study of COVID-19. A review. Science of The Total Environment, 739, 140033. PMID: 32534320; PMCID: PMC7832930. https://doi.org/10.1016/j.scitotenv.2020.140033. Epub 2020 Jun 8.

GBD 2016 Traumatic Brain Injury and Spinal Cord Injury Collaborators. (2019). Global, regional, and national burden of traumatic brain injury and spinal cord injury, 1990-2016: a systematic analysis for the Global Burden of Disease Study 2016. The Lancet Neurology, 18(1), 56-87. https://doi.org/10.1016/S1474-4422(18)30415-0.

Gugglberger, L. (2021). A brief overview of a wide framework-Health promoting schools: a curated collection. Health Promotion International, 36(2), 297-302. https://doi.org/10.1093/heapro/daab037

Harris, T. C., de Rooij, R., \& Kuhl, E. (2019). The Shrinking Brain: Cerebral Atrophy Following Traumatic Brain Injury. Ann Biomed Eng, 47(9), 1941-1959. https://doi.org/10.1007/s10439-018-02148-2

Harvey, L. A., \& Close, J. C. (2012). Traumatic brain injury in older adults: characteristics, causes and consequences. Injury, 43(11), 1821-1826. https://doi.org/10.1016/j.injury.2012.07.188

Ijumulana, J., Ligate, F., Bhattacharya, P., Mtalo, F., \& Zhang, C. (2020). Spatial analysis and GIS mapping of regional hotspots and potential health risk of fluoride concentrations in groundwater of northern Tanzania. 
The Science of the Total Environment, 735, 139584. https://doi.org/10.1016/j.scitotenv.2020.139584

Joyce, K. (2009). “To me it's just another tool to help understand the evidence": Public health decision-makers' perceptions of the value of geographical information systems (GIS). Health \& Place, 15(3), 831-840. Epub 2009 Feb 8. PMID: 19268622. https://doi.org/10.1016/j.healthplace.2009.01.004.

Juengst, S. B., Kumar, R. G., \& Wagner, A. K. (2017). A narrative literature review of depression following traumatic brain injury: prevalence, impact, and management challenges. Psychology research and behavior management. https://doi.org/10.2147/PRBM.S113264

Katarzyna, K., Agata, T., \& Marcin, M. (2019). Severe TBI patients benefit from multi-modal and multi-disciplinary treatments approaches-two exemplary case reports. Journal of medicine and life, 12(1), 71 . PMID: 31123528; PMCID: PMC6527415. https://doi.org/10.25122/jml-2019-0016

Kirby, R. S., Delmelle, E., \& Eberth, J. M. (2017). Advances in spatial epidemiology and geographic information systems. Annals of epidemiology, 27(1), 1-9. https://doi.org/10.1016/j.annepidem.2016.12.001

Kontopantelis, E., Springate, D. A., Ashworth, M., Webb, R. T., Buchan, I. E., \& Doran, T. (2015). Investigating the relationship between quality of primary care and premature mortality in England: a spatial whole-population study. Bmj, 350. https://doi.org/10.1136/bmj.h904

Li, M., Zhao, Z., Yu, G., \& Zhang, J. (2016). Epidemiology of traumatic brain injury over the world: a systematic review. General medicine: open access, 4(5), e275-e275. https://doi.org/10.4172/2327-5146.1000275

Long, X., Liu, F., Zhou, X., Pi, J., Yin, W., Li, F., ... \& Ma, F. (2021). Estimation of spatial distribution and health risk by arsenic and heavy metals in shallow groundwater around Dongting Lake plain using GIS mapping. Chemosphere, 269, 128698. Epub 2020 Oct 22. PMID: 33121802. https://doi.org/10.1016/j.chemosphere.2020.128698.

Maas, A. I. (2017). Traumatic brain injury in India: a big problem in need of data. Neurology India, 65(2), 257. https://doi.org/10.4103/0028-3886.201848. PMID: 28290383.

Maas, A. I., Menon, D. K., Adelson, P. D., Andelic, N., Bell, M. J., Belli, A., ... \& Francony, G. (2017). Traumatic brain injury: integrated approaches to improve prevention, clinical care, and research. The Lancet Neurology, 16(12), 987-1048. https://doi.org/10.1016/S1474-4422(17)30371-X.

Maegele, M. (2019). The long journey towards uniform epidemiological monitoring of TBI around the globe. Lancet Neurol, 18(3), 228-229. Epub 2019 Feb 12. PMID: 30784547. https://doi.org/10.1016/S1474-4422(19)30019-5

Maier, K. J., \& Al'Absi, M. (2017). Toward a biopsychosocial ecology of the human microbiome, brain-gut axis, and health. Psychosomatic medicine, 79(8), 947-957. https://doi.org/10.1097/PSY.0000000000000515.

Majdan, M., Plancikova, D., Brazinova, A., Rusnak, M., Nieboer, D., Feigin, V., \& Maas, A. (2016). Epidemiology of traumatic brain injuries in Europe: a cross-sectional analysis. The Lancet Public Health, 1(2), e76-e83. Epub 2016 Nov 29. PMID: 29253420. https://doi.org/10.1016/S2468-2667(16)30017-2

Majdan, M., Plancikova, D., Maas, A., Polinder, S., Feigin, V., Theadom, A., ... \& Haagsma, J. (2017). Years of life lost due to traumatic brain injury in Europe: a cross-sectional analysis of 16 countries. PLoS medicine, 14(7), e1002331. https://doi.org/10.1371/journal.pmed.1002331

Rytkönen, M. J. (2004). Not all maps are equal: GIS and spatial analysis in epidemiology. International journal of circumpolar health, 63(1), 9-24. https://doi.org/10.3402/ijch.v63i1.17542

Mollayeva, T., Sutton, M., Chan, V., Colantonio, A., Jana, S., \& Escobar, M. (2019). Data mining to understand health status preceding traumatic brain injury. Scientific reports, 9(1), 1-10. https://doi.org/10.1038/s41598-019-41916-5

Nayak, P. P., Pai, J. B., Singla, N., Somayaji, K. S., \& Kalra, D. (2021). Geographic information systems in spatial epidemiology: Unveiling new horizons in dental public health. Journal of International Society of Preventive \& Community Dentistry, 11(2), 125. Published 2021 Apr 15. doi:10.4103/jispcd.JISPCD_413_20

Nykiforuk, C. I., \& Flaman, L. M. (2011). Geographic information systems (GIS) for health promotion and public health: a review. Health promotion practice, 12(1), 63-73. https://doi.org/10.1177/1524839909334624.

Peeters, W., van den Brande, R., Polinder, S., Brazinova, A., Steyerberg, E. W., Lingsma, H. F., \& Maas, A. I. (2015). Epidemiology of traumatic brain injury in Europe. Acta neurochirurgica, 157(10), 1683-1696. https://doi.org/10.1007/s00701-015-2512-7. 
Saran, S., Singh, P., Kumar, V., \& Chauhan, P. (2020). Review of geospatial technology for infectious disease surveillance: use case on COVID-19. Journal of the Indian Society of Remote Sensing, 1-18. https://doi.org/10.1007/s12524-020-01140-5

Shaw, N., \& McGuire, S. (2017). Understanding the use of geographical information systems (GIS) in health informatics research: A review. Journal of Innovation in Health Informatics, 24(2), 228-233. https://doi.org/10.14236/jhi.v24i2.940

Vitaz, T. W., Jenks, J., Raque, G. H., \& Shields, C. B. (2003). Outcome following moderate traumatic brain injury. Surgical neurology, 60(4), 285-291. https://doi.org/10.1016/S0090-3019(03)00378-1

Wang, F. (2020). Why public health needs GIS: A methodological overview. Annals of GIS, 26(1), 1-12. https://doi.org/10.1080/19475683.2019.1702099.

Washnik, N. J., Anjum, J., Lundgren, K., \& Phillips, S. (2019). A review of the role of auditory evoked potentials in mild traumatic brain injury assessment. Trends in hearing, 23, 2331216519840094. https://doi.org/10.1177/2331216519840094

\section{Copyrights}

Copyright for this article is retained by the author(s), with first publication rights granted to the journal.

This is an open-access article distributed under the terms and conditions of the Creative Commons Attribution license (http://creativecommons.org/licenses/by/4.0/). 